\title{
Green Construction Technology of Algeria North-South Expressway
}

\author{
Daiguang Chen,a, Likui Huang ${ }^{1, b}$,Enkuan Tang ${ }^{2, c}$, \\ Wenbin $\mathrm{Wu}^{1, \mathrm{~d}}$, Qing Shen ${ }^{1, \mathrm{e}}$ \\ ${ }^{1}$ College of Civil Engineering, Hunan University, China \\ ${ }^{2}$ China Construction Fifth Engineering Bureau Co. LTD \\ achendaiguang@cscec.dz, bhuanglikui@hnu.edu.cn, tangenkuan@cscec.dz, \\ dwuwenbin@hnu.edu.cn, eshenqing@hnu.edu.cn
}

Keywords: green construction, expressway, EPC mode, International engineering Abstract: The Algeria North-South Expressway from Chiffa to Berrouaghia is located in Blida province and Medea province in northern Algeria, with the route along the Chiffa river valley, through the national park in Algeria, large tracts of vineyards and other agricultural land in Medea privince, and bypassing the Berrouaghia residential areas. It is very strict with the environment protection. The project adopts EPC mode for construction, and establishes a complete set of green construction technology for expressway in green design concept, green environmental protection material and green construction technology innovation, by taking full advantage of the integration of design, construction and procurement.

\section{Project Overview}

The Algeria North-South Expressway from Chiffa to Berrouaghia is located in Blida province and Medea province in northern Algeria, with a length of $53.6 \mathrm{~km}$. It is the beginning section of the North-South Expressway in the Algeria national arterial highway networks composed of two latitudinal and one longitudinal highways. As an important part of the main highway skeleton in Algeria, the expressway from Chiffa to Berrouaghia is responsible for the main function of traffic conversion between plateau and coastal areas in the country. The project location is shown in figure 1.

The route is along the Chiffa river valley, through the national park of Algeria, large tracts of vineyards and other agricultural land in Medea, and bypassing the Berrouaghia residential areas. It is very strict with the environment protection. The project adopts the EPC (design + purchase + construction) mode for construction. The strict technical requirements of the owner about the environment and resources along the route are well met using a variety of green building technology innovation.

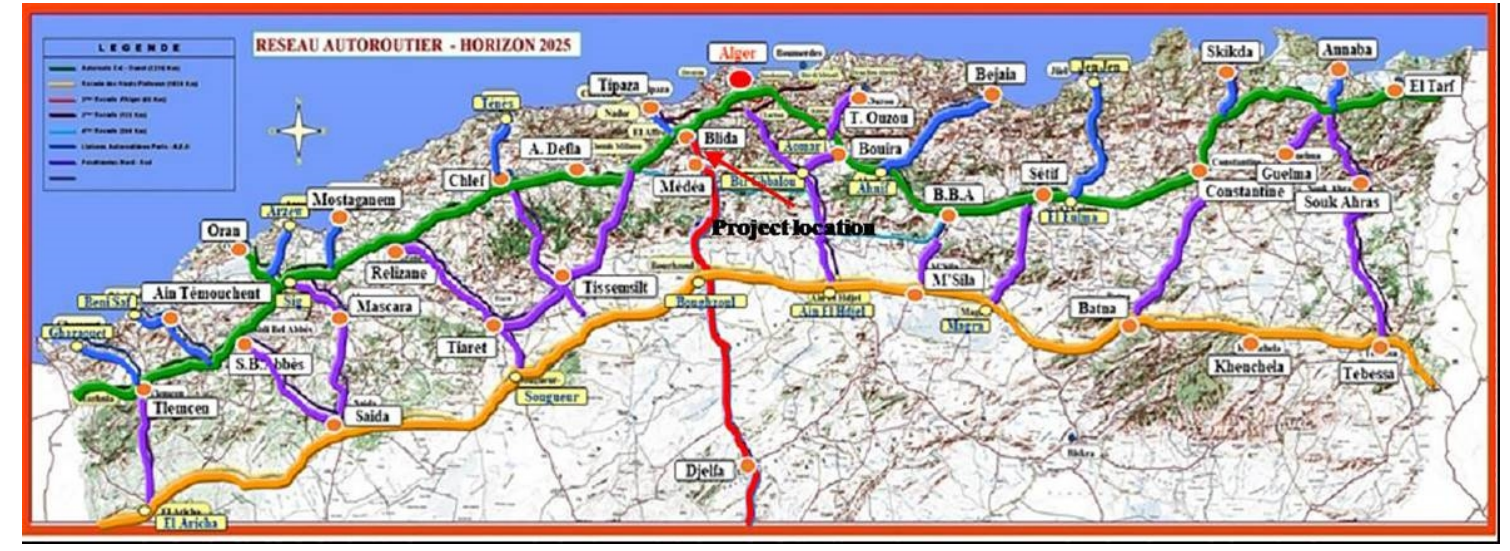

Fig. 1 Geographical location map of the project 


\section{Green Construction under EPC Mode}

EPC - turnkey project mode is adopted in this project, which reflects the integration advantages of design, construction and procurement. It conforms to European norms, advocates the concept of harmony in China, and adapts to the Algerian environment. A unique set of green construction techniques is developed. The main features are as follows:

w The green design concept contains devoting to restoring vegetation, conservation of soil erosion, protecting the ecological environment of animals and plants, and avoiding the island effect. It also contains protecting local waters, reducing noise pollution and man-made external damage factors, and construction of harmony between engineering and natural environment.

w Application of green materials contains building materials that are obtained from the nature as far as possible, reducing the environmental damage of resources, replacing ordinary products with environmental technology.

w Implementation of green construction technology contains localization of vegetation species, continuation of species, reducing the pollution of water, dust and noise, avoiding encroachment on land resources, and devoting to saving, implementation of standardized production.

\section{Typical Green Building Technology}

In the construction of the expressway project in Algeria, the European highway construction standard system is mainly adopted. With the integrating Chinese philosophy and introduction of China's advanced green construction technology, the concept of green construction with Algerian and Chinese characteristics is formed. The concept of green construction is to realize the harmony of environment, harmony of resources and social harmony through green design, procurement and construction.

\section{Harmony with the Environment}

The expressway construction will inevitably affect the environment along the highway. In the construction process, the following technical measures to realize the harmony of expressway engineering and surrounding environment are mainly adopted.

Optimization of road route for protection of rare animal barbary apes in Algerian. The barbary ape is a kind of animals national-protected in Algerian, and they just live in Chiffa canyon where there is plenty of water, no pollution, fresh air and pleasant weather. To protect the living environment of barbary apes, the highway route is optimized in the construction drawing design. The route keeps away from Chiffa canyon, and passes through the monkey hill and national geopark by tunnel, as shown in figure 2.

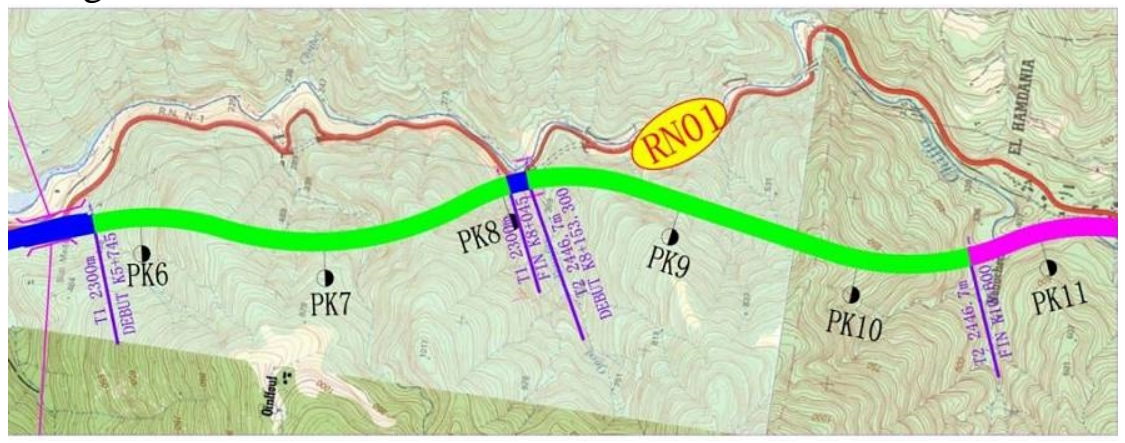

Fig. 2 Route optimization to protect the habitat of barbary apes

Reducing noise. Concrete barrier, corrugated fence and mound wall are set up to reduce the influence of road traffic noise on the residents on both sides of the road, as shown in figure 3 .

Setting animal channel. For the convenience of local frog, wild boar, no tail monkey and wild wolf migration, special access roads and viaducts for animals are set up, the expressway is equipped with a special passage or viaduct for animals, in case the effect of survival in seperate islands has adverse effects on wildlife, as shown in figure 4. 
Setting the Atalus retaining wall. To reduce the amount of concrete, beautify environment along the line, Atalus retaining wall is used in many places along the line. The retaining wall is similar to China's flexible retaining wall, and the exterior wall decoration is made of precast block, planting flowers and plants between the gap of precast block, as shown in figure 5.

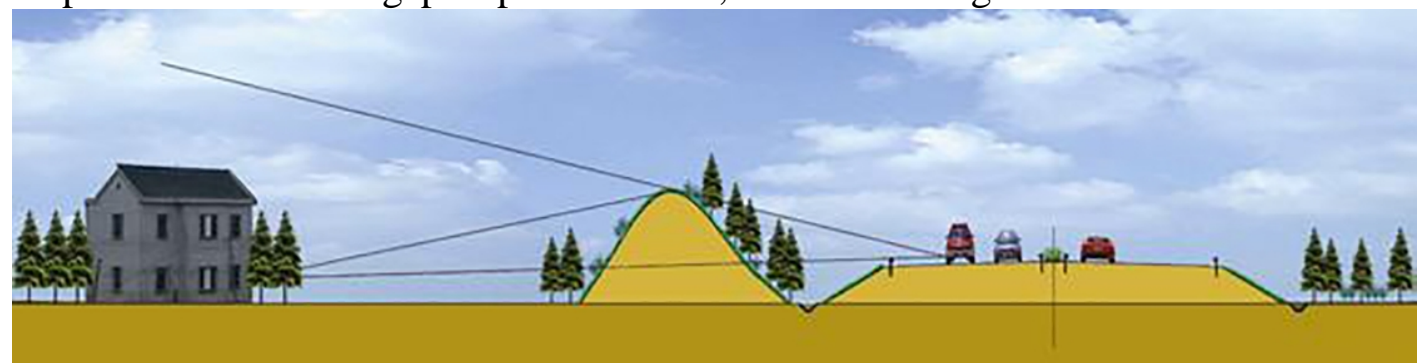

Fig. 3 The roadbed mound partition wall

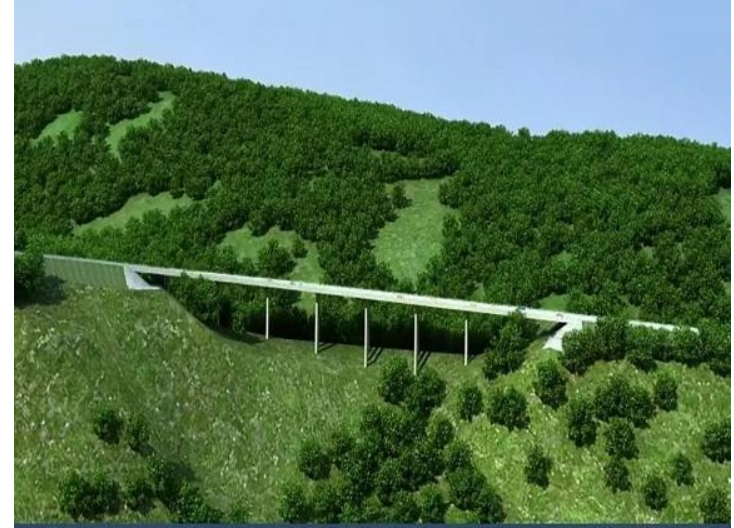

Fig. 4 Wildlife channel
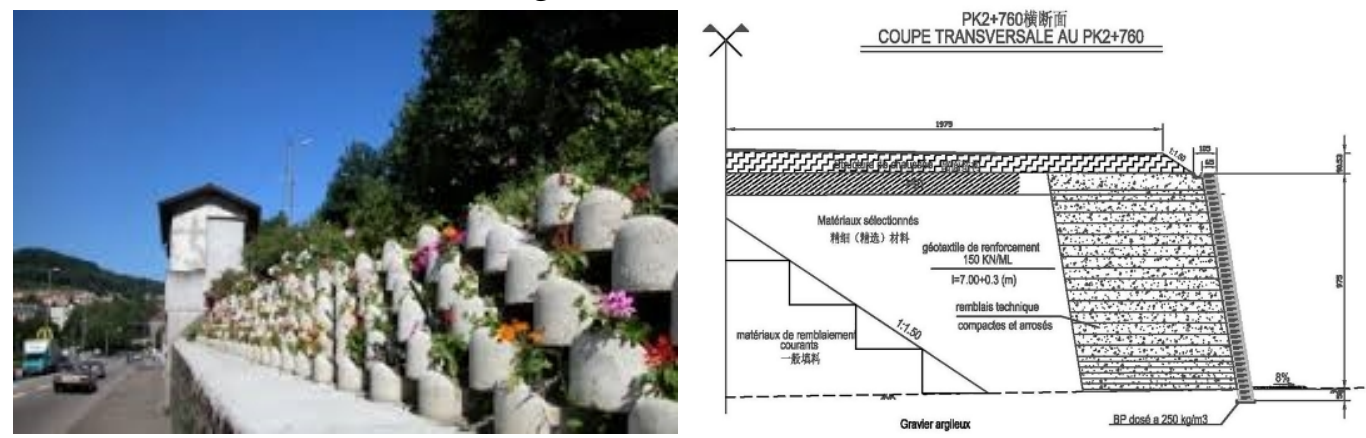

Fig. 5 Atalus retaining wall

Green ecological slope protection. The slope protection design of roadbed is diverse, and the greening of the interchange area is combined with macrophanerophytes and flowers. Slope greening is combined with shrubs and flowers, seeding in hollow precast block for bridge head cone slope protection, building the green ecology within the red line of the expressway through these methods.

Ecological restoration of spoil ground. The greening plan of spoil ground is planned in advance, in the construction, and the ecological restoration of the abandoned soil is strengthened to ensure the ecological restoration, as shown in figure 6.

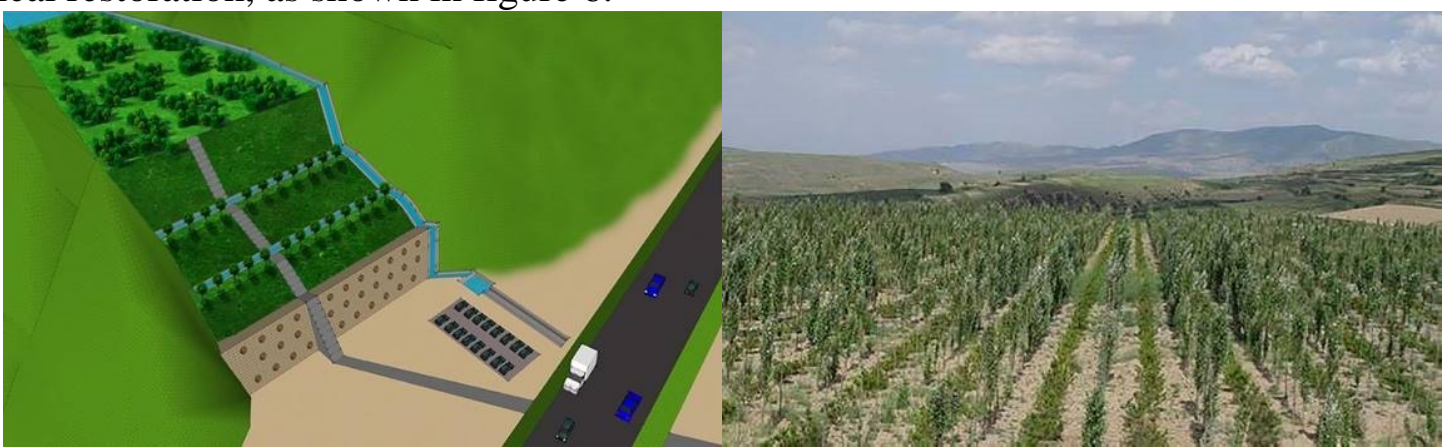

Fig. 6 Ecological restoration of spoil grounds 
Green construction of pile foundation. The rotary drilling rig is used to drill into holes to realize rapid construction and reduce the discharge of slurry. The project has 6927 piles, so the effect on the environment is clear, as shown in figure 7.

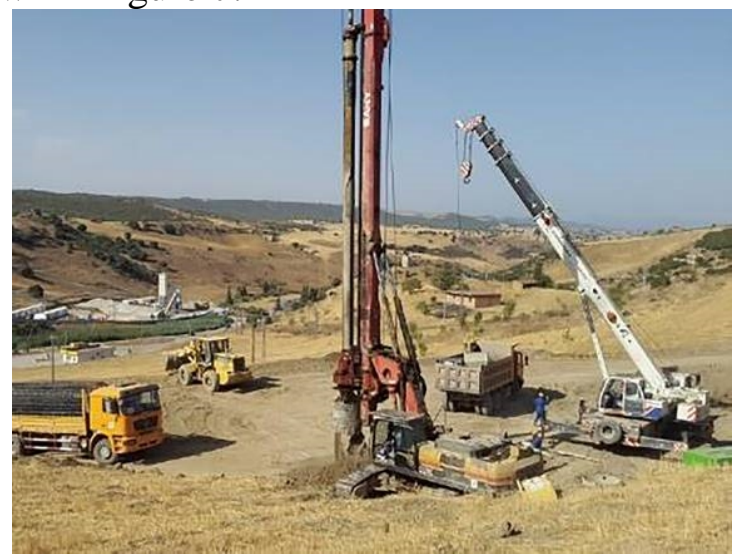

Fig. 7 Construction of green pile foundation

Protection of local waters. Tertiary sedimentation tank should be set up in life camp, production camp and tunnel import and export, and sewage must be precipitated or chemically purified before it can be discharged. It effectively protects the environment of local waters, as shown in figure 8 .

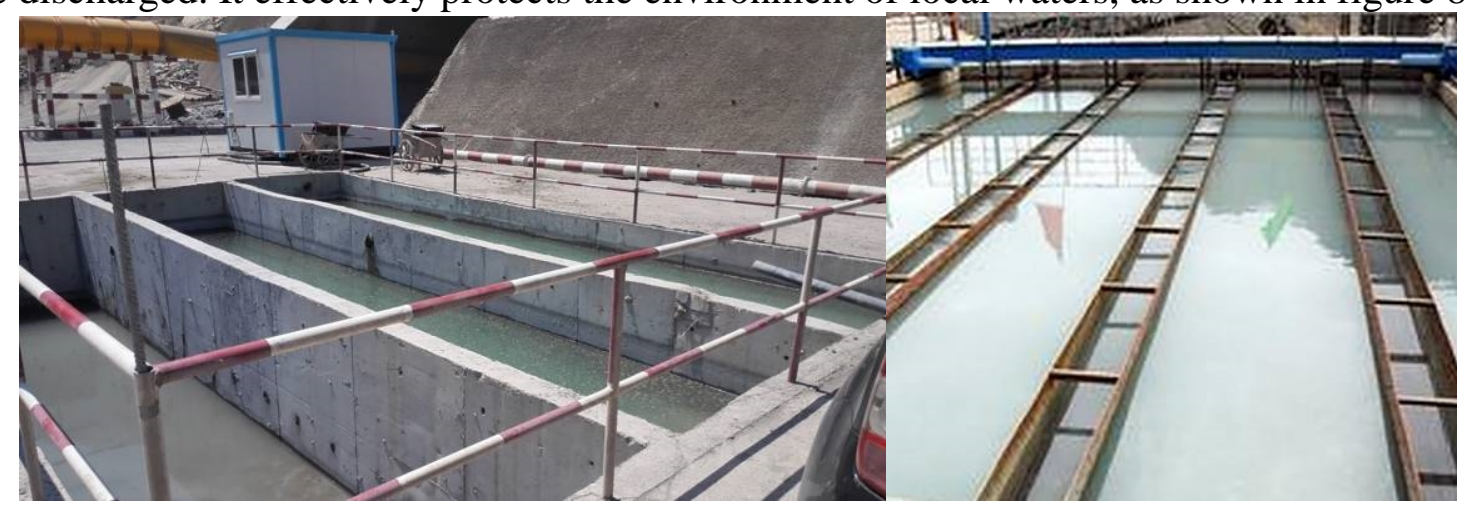

Fig. 8 Tertiary sedimentation tank of purified water

Plant dazzle-resistant design for tunnel entrance. The concrete frame protection is set up in 8 holes of 2 tunnels. Shrubs and flowers are used for beautifying, and integrating with the surrounding environment to achieve the reducing light and anti-glare effect. The safety and comfort of driving are improved effectively, as shown in figure 9.

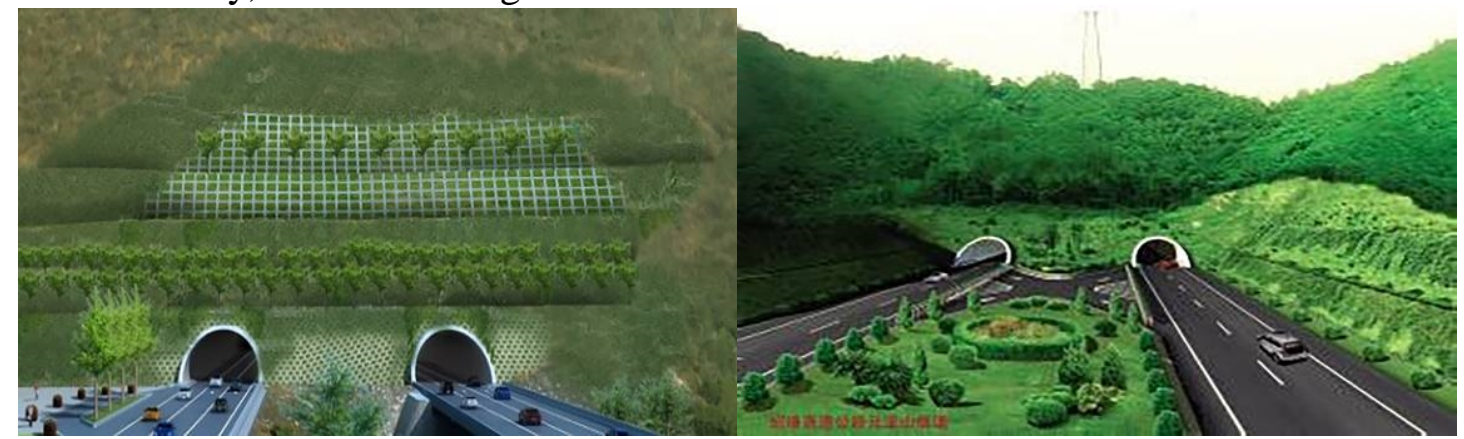

Fig. 9 Plant anti-dazzle design for tunnel entrance

\section{Harmony with Resources}

Compared with China, Algeria is relatively short of material resources. Cement production is deficient, and often cannot be supplied on time. Steel and construction machinery need to be imported completely. Although the country is a crude exporter, refined oil needs to be imported, and sometimes the whole country is suffering from oil shortage. The country is large in size, but most areas are gobi and deserts, and they are only suitable for living and agricultural production along the mediterranean coast. In the case of such a shortage of materials, expressway construction needs to be rationally allocated resources, save resources, and achieve the harmony between expressways and resources. 
Application of slide-resistant shovel technology. In order to save the land, the slope toe foundation should be strengthened, and a groove should be dug at slope toe. Geotextiles is used to cover the stone.

Bridge standardization technology. The preliminary design has 30 steel composite beams, and 27 of them are cast-in-place concrete beam. $50.6 \mathrm{~m} / 36.1 \mathrm{~m} / 28.1 \mathrm{~m} / 20.6 \mathrm{~m}$ prestressed $\mathrm{T}$ beam is adopted in the design of construction drawings. The practising of bridge standardization technology saves a lot of material resources, as shown in figure 10.
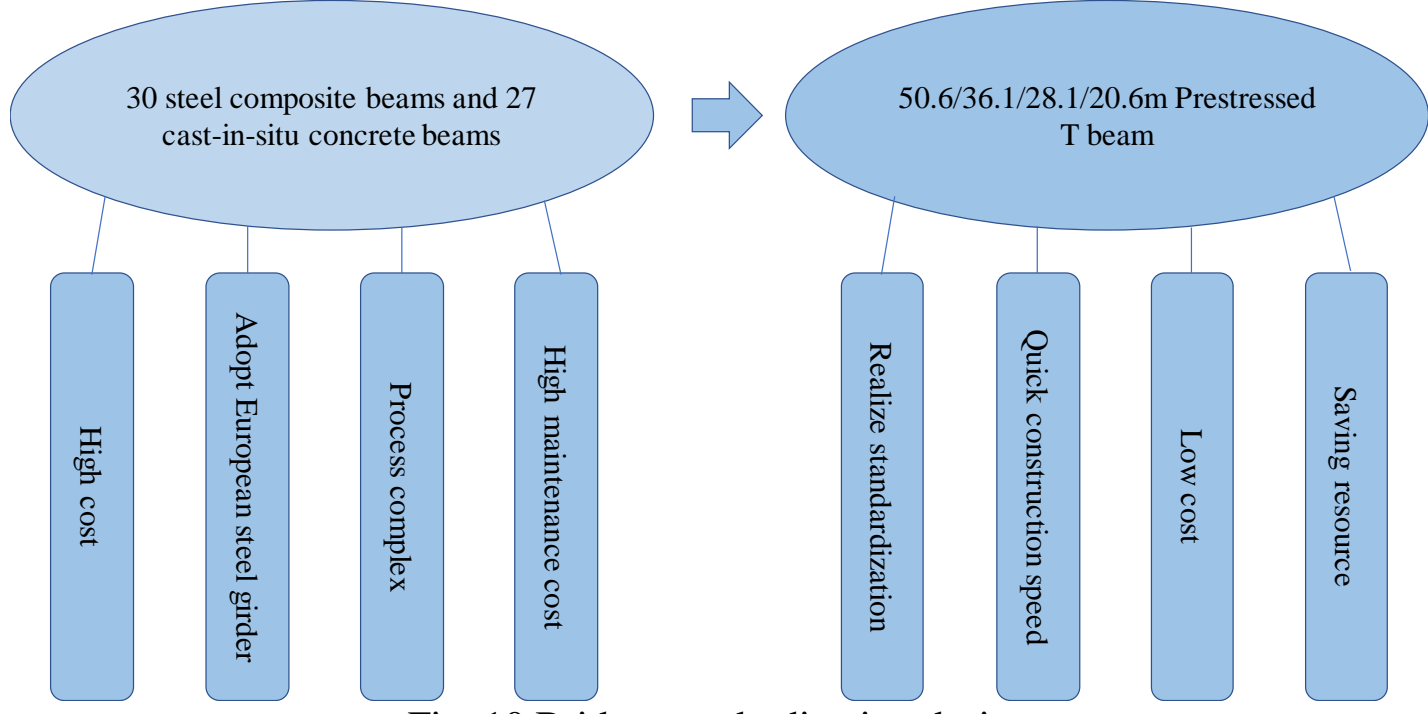

Fig. 10 Bridge standardization design

Multi-function $\mathbf{T}$ beam prefabricated platform. The same multi-functional platform is suitable for $\mathrm{T}$ beam prefabrication of $20 \mathrm{~m}, 28 \mathrm{~m}, 36 \mathrm{~m}$ and $50 \mathrm{~m}$, saving the land, as shown in figure 11 .

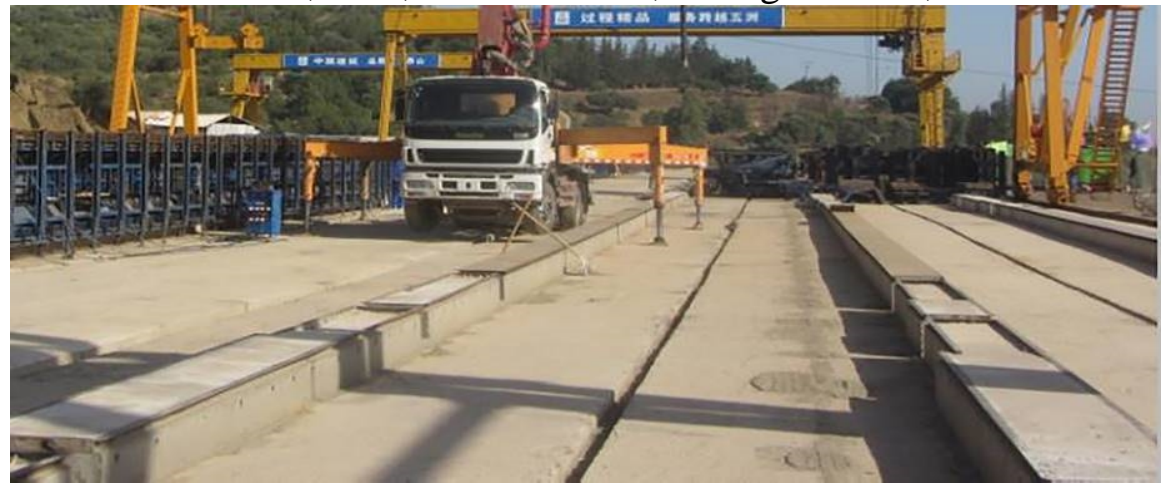

Fig. 11 Multi-function T beam prefabricated platform

Application of drain board in tunnel. The design of tunnel drainage is optimized, and the drainage plate is used to replace the drainage blind pipe, which can improve the drainage effect and save the engineering materials. The installation method is basically the same as that of the waterproof sheet for protecting the geotextile, do not interfered with by the second liner reinforcement, and the operation is simple.

Tunnel lighting intelligent regulation system. Adopted the intelligent adjustment system of tunnel lighting in the later operation, the dimming control is based on the brightness and traffic to realize on-demand lighting, and greatly reduce lighting energy consumption, as shown in figure 12. 


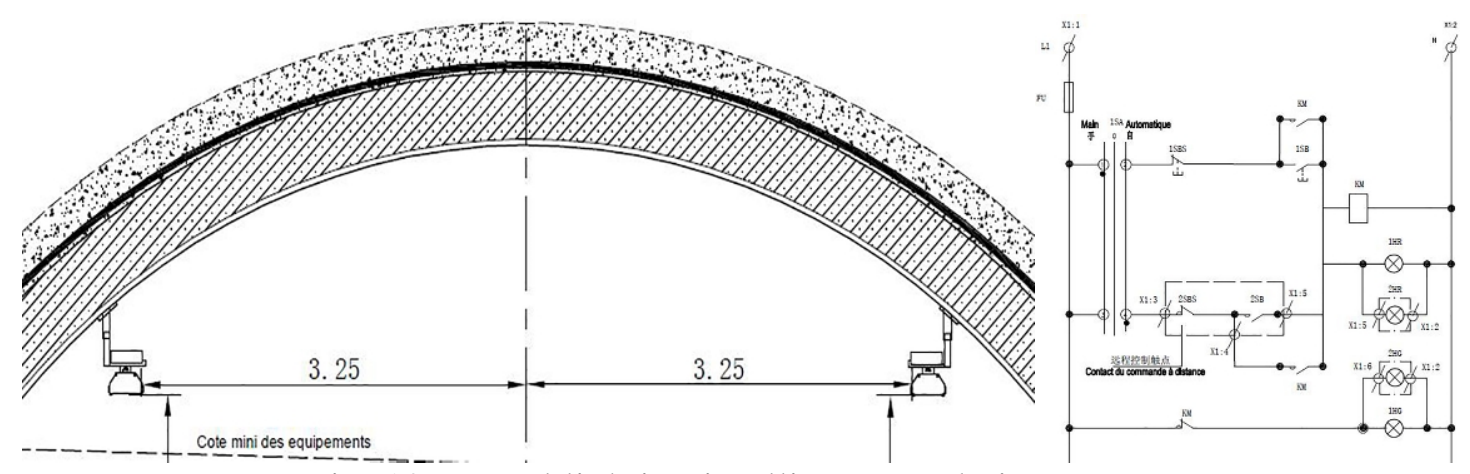

\section{Harmony with Social}

Fig. 12 Tunnel lighting intelligent regulation system

China State Construction Engineering has entered the Algerian market for more than 30 years, gradually familiarize themselves with the way of life of the country's people and the way government agencies operate. Algeria is a religious country, the people are predominantly belief Mohammedanism. In the construction of the project, attention should be paid to humane protection, especially cultural relics and ancient towns. The local customs and the religious beliefs of the islamic people should be respected. Local labor resources should be used as much as possible to expand employment channels, improve local people's building skills, and achieve project construction and social harmony.

The ancient town protection. In the design stage of construction drawing, consideration is given to the reasonable spacing of intercommunication, expected traffic volume and traffic safety, after route optimization design, the interchange design of Hamdania town was cancelled, realize the vehicle up and down the expressway in the RN01-CW62-CW87, which is $2.5 \mathrm{~km}$ south of the town, it protects the town of Hamdania.

Respect local religious beliefs. In the construction of the project, Take the initiative to repair the road to the nearby mosque, convenient for local villagers to worship.

Endowed vocational college. To improve the skills of local people, broaden their employment channels and build a vocational college for local donors.

\section{Conclusion}

The Algeria North-South Expressway from Chiffa to Berrouaghia is located in Blida province and Medea province in northern Algeria, with the route along the Chiffa river valley, through the national park in Algeria, large tracts of vineyards and other agricultural land in Medea privince, and bypassing the Berrouaghia residential areas. It is very strict with the environment protection. The project adopts EPC mode for construction, and establishes a complete set of green construction technology for expressway in green design concept, green environmental protection material and green construction technology innovation, by taking full advantage of the integration of design, construction and procurement.

\section{References}

[1] China State Construction Engineering Algeria North-South expressway project. Special technical terms for the north-south highway in Algeria (CCTP) [Z], 2014.

[2] China State Construction Engineering Algeria North-South expressway project. Construction drawing design document of Algeria North-South expressway [Z], 2015.

[3] Industry standards of the People's Republic of China. Design Specification for Highway Alignment (JTG D20-2006) [S], 2006.

[4] Ictaal Instruction Sur Les Conditions Techniques D'AMÉNAGEMENT Des Autoroutes De Liaison. France: Serviced d'Etudes Techniques des Routes et Autoroutes. 2000. 